\title{
Pasifika student experience in a Bachelor of Midwifery programme
}

Deb Beatson ${ }^{A, B}$ PGDip Mid, RM - Anna Seiuli ${ }^{B}$ NatDipCouns, DipAppSoS, BSS - Jean Patterson ${ }^{B}$ PhD, RM - Christine Griffiths ${ }^{B}$ PhD (Cand), MA, RM • Kerrie Wilson ${ }^{B} M B A, B A$

\author{
${ }^{\text {A Corresponding }}$ \\ Author: deb. \\ beatson@op.ac.nz

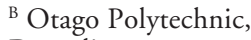 \\ Dunedin
}

\begin{abstract}
Background: In New Zealand the Pasifika population comprises 6.9\%. Rapid growth in the Pasifika population is anticipated and, with only $2.2 \%$ of registered midwives identifying as Pasifika, most Pasifika women are currently, and could increasingly be, unable to access a midwife from their culture. To help address this need Otago Polytechnic has identified Pasifika midwifery student success as a priority area.

Aim: The objective of the research was to hear how Pasifika students experience studying midwifery, and to seek their contribution to the ongoing development of the learning environment and School processes, with the aim of increasing their enjoyment, success and retention rate in the programme.

Method: Possible methodologies were considered, with the aim of developing a culturally appropriate relationship between the researcher and the participant. The Talanoa and the Kakala research approaches informed how the students were approached and the interviews conducted. To help frame the research, a flexible participatory model, "Spacifichology", was chosen which recognises four categories of Pasifika learners. Following ethical approval, individual interviews were undertaken by the Pasifika researcher with the participants. The recordings were transcribed and analysed for themes.

Findings: Two broad areas were uncovered. Firstly, "the experience of being Pasifika" with subthemes: trying to fit in; it's not easy to ask for help; determination to succeed; and the desire to work with Pasifika women. And, secondly, "the student experience in the programme" with subthemes: the value of àkonga (local tutorial groups); the costs of the programme; assignment writing; preferring face-to-face; making connections: a place to belong; and collectivism (it is about us).

Conclusion: Pasifika students are challenged by competing demands from family, social responsibilities, financial issues and unfamiliarity in the tertiary education environment. Fostering a "learning village" will help students to feel like they fit in. As educators, it is crucial for us to understand that it is always about "us" for Pasifika students; not about them as individuals. Finally, these Pasifika students are determined to succeed.
\end{abstract}

Keywords: Pacific, Pasifika, undergraduate midwifery education, midwifery student

\section{INTRODUCTION}

The word "Pasifika" refers to learners and communities or populations of peoples living in Aotearoa New Zealand (NZ) who have genetic and cultural links to Pacific Island nations. More than 15 Pacific nations fall under the umbrella of Pasifika and each culture is unique. In 2010 the Pasifika population comprised $6.9 \%$ of the NZ population (Statistics New Zealand \& Ministry of Pacific Island Affairs, 2010). The number of Pacific people in NZ is growing rapidly, with Samoans the largest Pasifika ethnic group and Tongans the most rapidly growing group (Statistics New Zealand \& Ministry of Pacific Island Affairs, 2010), influencing the demographic and cultural profile of NZ.

Currently, the majority of Pasifika people resident in NZ have been born here. This is a change from a previously mainly migrant group (Statistics New Zealand \& Ministry of Pacific Island Affairs, 2010). Further, the Pasifika population is considerably younger, with a median age of 21 years, compared with 36 years for the total population of NZ (Statistics New Zealand \& Ministry of Pacific Island Affairs, 2010).
Chu, Samala Abella and Paurini (2013) acknowledge that Pasifika are over-represented in low-decile schools and may not have been provided with the same learning opportunities as other students. As a consequence, Pasifika are under-represented in professional roles, prompting Alkema (2014) to suggest that tertiary institutions need to be cognisant of this and have strategies to support Pasifika students to succeed.

When we began this current study, midwives in NZ identifying as Pasifika represented only $2.2 \%$ of registered midwives (Midwifery Council of New Zealand [MCNZ], 2014). Therefore, most Pasifika women will be unable to access a midwife from their culture.

\section{BACKGROUND}

In the Bachelor of Midwifery programme at Otago Polytechnic we have a small number of students who identify as Pasifika. Some of these students are challenged by the academic expectations and the workload required in the programme. At the time of this study we had an $81 \%$ retention rate for Pasifika students, with the course completion rate averaging 73\% between 2012 and 2014. The success of these students is a priority for our School of Midwifery, 
and Otago Polytechnic has clearly identified Pasifika student success as a priority area for all schools, with the intention of building a tertiary system where Pasifika students are encouraged and supported to succeed (External Pacific Advisory Committee, 2014). This project is viewed as a starting place to understand more clearly the issues for Pasifika students within a particular School and where resources can be directed.

In 2014 a study was designed with the aim of hearing the voices of Pasifika midwifery students to inform how we could support them in the programme. This followed a participatory research project undertaken in 2013 with Māori students in the School using a kaupapa Māori process and methodology (Patterson, Newman, Kerkin, \& Wilson, 2013), from which the School made changes to the teaching practices and processes in response to the student recommendations. Our research question for the Pasifika study was similarly aimed at discovering the experiences of Pasifika students and, where possible, making changes to increase their enjoyment, success and retention in the programme.

Three lecturers and a Student Advisor in the School of Midwifery, in collaboration with the Otago Polytechnic Pasifika Student Advisor, undertook the study.

\section{Bachelor of Midwifery programme}

The current Otago Polytechnic Bachelor of Midwifery programme was jointly designed and developed by Otago Polytechnic and Christchurch Polytechnic Institute of Technology (now Ara Institute of Canterbury) and commenced in 2009. The curriculum uses a blended delivery model to meet the MCNZ standards (MCNZ, 2015) and improve access and local midwifery practice opportunities for students. The degree is a three-year programme (equivalent to four years' full-time study) delivered over 45 programmed weeks in each year (MCNZ, 2015).

The blended model allows us to support students to undertake the majority of their study in their home areas and includes:

- a range of online learning resources

- distance synchronous online tutorials using the Adobe Connect $^{\mathrm{TM}}$ platform

- ākonga (local tutorial groups) where a local midwifery kaiako (lecturer) supports a small group of up to seven students

- face-to-face learning blocks (known as "intensives") at the Dunedin and Kāpiti campuses

- midwifery practice experiences in rural and provincial areas, as well as in main centres

There are satellite groups in Whanganui, Palmerston North and the Wellington area in the North Island, and in Central Otago, Southland and Dunedin in the South Island. Ākonga groups meet weekly for three or four hours in years one and two, providing opportunities for debriefing, learning and practising midwifery skills, and the provision of pastoral support.

\section{Literature review}

While it is acknowledged that there is minimal research in the area of Pasifika tertiary education, Ako Aotearoa (National Centre for Tertiary Teaching Excellence) has led the way with research examining Pasifika student success. Alkema (2014) reported to Ako Aotearoa, identifying key findings from 11 projects between 2008 and 2013. These findings support the enhancement of educational outcomes for Pasifika learners in tertiary education. They conclude that organisations need to take a holistic approach with Pasifika learners, providing a "learning village", supporting students academically and pastorally in an environment where they feel comfortable. The recommendations were that ongoing work in the area of supporting Pasifika student success should focus on the links between interventions and retention, quantifying what makes a difference to learner outcomes, rather than focussing on literature reviews (Alkema, 2014).

Since this report, there has been a mixed methods study exploring Pasifika learner voices to identify and build on strategies that support learner success within Canterbury (Luafutu-Simpson et al., 2015). A Pasifika methodology, the Fausiga O Le Fale Tele Model, was used with focus groups and the findings demonstrated that Pasifika students' perception of what success means to them is tightly linked to their families and communities. For success, transformative changes in the academic interface, organisation practices and engaging spaces were recommended. The visibility of Pasifika culture within course content and curriculum design was seen as important, and both the learning contexts and teaching approaches need to enable Pasifika collectivist values. Further, organisational practices with targeted Pasifika learner support, and opportunities to meet with the wider Pasifika communities, were advocated to increase community connectedness. Finally, the provision of informal meeting spaces with visual imagery and artwork which reflect Pasifika culture was recommended (Luafutu-Simpson et al., 2015).

In relation to midwifery education, a set of specifications to guide good practice, quality improvement and aspirational goal setting was developed, based on the Future Workforce (2009) report. The recommendations followed a survey of tertiary institutions and District Health Boards (DHBs) of the undergraduate education and clinical placement experiences of Māori and Pacific nursing and midwifery students. The specifications targeted at the Schools of Midwifery and the Schools of Nursing included providing early counselling options when students consider leaving, requiring all students to attend an exit interview, and providing students with scholarship information and sources of advice on financial matters (Future Workforce, 2009).

Findings included that Pacific students may take longer to complete undergraduate degrees and have higher attrition rates than other nursing and midwifery students (Future Workforce, 2009). Interestingly, it was suggested that Schools with small numbers of Māori and Pacific students appear to have better retention rates and students are more satisfied with their support services. At Otago Polytechnic we have small numbers of Pasifika students enrolling in the midwifery programme. The Future Workforce survey did not gather data directly from students but rather gathered demographic and anecdotal data from the schools and DHBs. Our study addresses this gap by seeking to hear the students' voices.

This brief review of the literature highlights that there has been some exploration of the factors that encourage/hinder Pasifika student success but it is an area that needs further research. This study builds on the findings in the above literature by adding the particular experiences of the participating midwifery students who represent a minority group in the Bachelor of Midwifery programme at Otago Polytechnic.

\section{METHOD}

To guide this research, we explored possible Pasifika research approaches. The aim was to foster a culturally appropriate relationship between the researcher and this small number of participants. Two models were chosen: Talanoa and Kakala.

Talanoa is a Tongan perspective which captures traditional ways of communicating concepts and values in common with many 
other Pacific nations (Vaioleti, 2006). One example is the mo'oni or "pure, real and authentic" (Vaioleti, 2006, p.1) approach, where the participants tell their story and aspirations in a very personal way, similar to a grounded theory approach. This can help balance the power dynamic between the researcher and the participants. Thus, Talanoa weaves culture, or the cultural experience of participants, into their narratives (Vaioleti, 2006). Also appraised was the Tongan Kakala process (Chu et al., 2013). This is similar to an appreciative inquiry approach (Cooperrider \& Whitney, 2005), where the historical and cultural wealth of the participants is the beginning point for the research. For this study these approaches, using traditional ways of communicating and valuing the cultural wealth of the participants, informed how the Pasifika researcher approached and negotiated the interview processes with the students.

However, Pasifika students come from at least 15 diverse nations, all with particular cultural and linguistic differences. These identities become even more complex when they move to NZ. Seiuli (2013) captures this complexity, which she termed "Spacifichology", which recognises four categories of Pasifika learners:

- learners born and raised in the Islands with Pasifika parents

- learners born in the Islands but raised in NZ with Pasifika parents;

- learners born and raised in NZ with Pasifika parents

- learners born and raised in NZ with one non-Pasifika parent

The model is created from three core aspects of Seiuli's work. It is "specifically" for "Pasifika" and takes a "psychological" view of Pasifika students as they function in NZ and reflects the only common factor that all Pasifika peoples share-their or their family's migration and now residency in NZ. By incorporating this model, there is potential to frame the student experiences and perhaps glean a deeper understanding of the challenges and potential of the students in the specific categories.

Overall, Seiuli's objective was to create a safe arena for the research team to learn and analyse each narrative without fear of offending Pacific cultures. The inclusion of Talanoa practices enabled the Pasifika researcher to focus on students' holistic journeys from their (or their family's) arrival into NZ to the present moment, and on the aspects of this experience that enabled or hindered their success in their midwifery programme (Seiuli, 2013).

Informed by these approaches, the goal was to record informal conversations with each of the participants on the key aims of the research. The process undertaken is outlined below.

Ethics approval for the research was sought and obtained from the Otago Polytechnic Research Ethics Committee (OPREC \#605).

\section{Participants}

Three students who identified as Pasifika, who were enrolled in the midwifery programme at that time, were approached by the Pasifika researcher and agreed to participate. This captured the total population of Pasifika students at the time; however, it is acknowledged that the small number of participants is a limitation of this study. Two students who had left the programme were approached but decided not to participate. The preliminary meeting was held in the local area of the participant/s. A koha (gift) of food and petrol vouchers, to acknowledge any travel costs, was offered as a traditional way of engagement. The research project was explained by the Pasifika researcher which included the return of the consolidated data to the participants for their approval before being presented to the School research team.
The individual interviews were undertaken at a second visit, later in the year, which allowed time for the students to consider whether or not they would participate. Each participant agreed to sign a consent form and koha was again provided. Participants were asked about their experience in the programme, what they saw as their learning needs, and what ideas they had for how learning resources and School processes could be adapted to improve their learning experiences. The Pasifika researcher digitally captured their comments, concerns and recommendations.

Understanding the individual participant's background helped guide the Talanoa (conversations). Using the Spacifichology model, our participants sat under categories 2 and 4 of the tool:

- Student \#1 \& Student \#2: Pasifika learners born and raised in NZ with Pasifika parents. Learners in this category often live by or are influenced by NZ values and beliefs. They often describe frustration at being stereotyped or experiencing assumptions from others that English is their second language (Seiuli, 2013).

- Student \#3: Pasifika learner born and raised in NZ with one non-Pasifika parent. Learners in this category might not be struggling with transitioning within the education system but they may be struggling with finding their identity within the continuum from Traditional to Postmodern culture, Pasifika values and beliefs. Learners may refer to themselves as "plastic"; that they are not real Pacific Islanders (Seiuli, 2013).

\section{Analysis}

A research assistant, who had signed a confidentiality agreement and was not associated with the School teaching team, transcribed the recordings. Identifying details were removed from the transcripts which were disseminated to the research team for analysis.

To analyse the data, the Pasifika researcher colour coded participants' transcripts and identified broad themes. The wider research team then met to review the data and the themes were refined.

A draft report was completed and forwarded to the participants to review, to correct any inaccuracies, and to provide any further feedback on the recommendations and conclusions.

Two broad areas emerged: firstly, the experience of being Pasifika and, secondly, the student experience in the programme (Table 1).

\begin{tabular}{l|l} 
Table 1: Themes \\
$\begin{array}{l}\text { Experience of being } \\
\text { Pasifika }\end{array}$ & $\begin{array}{l}\text { Student experience in the } \\
\text { programme }\end{array}$ \\
\hline Trying to fit in & $\begin{array}{l}\text { The value of ākonga } \\
\text { The costs of the programme } \\
\text { It's not easy to ask for help }\end{array}$ \\
Determination to succeed & $\begin{array}{l}\text { Assignment writing } \\
\text { Desire to work with Pasifika women }\end{array}$ \\
& $\begin{array}{l}\text { Preferring the face-to-face } \\
\text { Making connections } \\
\text { Place to belong } \\
\text { Collectivism }\end{array}$ \\
\hline
\end{tabular}

The experience of being Pasifika was about trying to fit in with the more dominant cultural groups, not wanting to stand out by asking for help, and having a strong personal and family-driven desire to succeed and to contribute their skills to their Pasifika communities. Whereas, the student experience in the programme largely embraced the challenges of the mix of learning modes and social connection aspects, in relation to their fellow students. 


\section{FINDINGS}

\section{Experience of being Pasifika - what the students bring to the programme}

Each student comes from a different background, which has influenced how each engages with the programme. One student stated:

I'm quite involved with the church. I don't have a family of my own; I don't have kids of my own, which frees me up quite a lot. But then I do help with my sister's kids quite a lot and extended family kids quite a bit; nieces and nephews. I suppose that's all part and parcel of being an Islander. (\#1)

Another student mentioned that "Probably a major part of [doing midwifery] is following what God wants me to do" (\#3).

This same student was asked if she was struggling to blend her knowledge as a Pacific person into what she was learning through the School. She responded:

Yup. I'm always looking for ways that I can get it in there. I just struggle that there's not that component. Well, it's almost like it's a cursory acknowledgment that they've just kind of thrown in. Very much a box ticking exercise. For me it would be great if there was more of a component there. (\#3)

Another student alerted us to her difficulty with the way things are introduced and presented to students:

For me it felt harder because my understanding of how things are put out is a little bit upside down.....It's really structured in a way that, sure, I went to school here and I understand that, but I still lived a Pacific life. I may have grown up in the school system, but I grew up in a Samoan house with the same Samoan ways of life, I suppose. (\#2)

This comment indicated that she had to work hard to decipher what the lecturers were meaning and requesting.

\section{Trying to fit in}

The students discussed the struggle with being Pasifika and trying to fit in. One student talked about heading to Dunedin for the initial orientation week:

Thinking back I can say it was really difficult, but at the same time I wasn't in a space to... I don't think I was that open myself. I was very closed, very suspicious, wary of these people and who they are and what are they actually going to do for us? (\#2)

It was identified that linking up with other students was helpful: "I think it was a relief to see other Mãori and Pacific students when I got there. It's funny because you just get drawn together. We all just sort of came together and hung out" (\#2).

She also recognised her unfamiliarity with the tertiary environment: "I've done life but I haven't done academic stuff to this extent" (\#2).

There were some surprising findings relating to fitting in, with the same student saying:

Yup, and to fit in. The other issue I have is, I'm quite big. I'm not a small person, so I can't just slink into the corner and, "Don't see me, don't see me!" I'm quite a large... you know? (\#2)

\section{It's not easy to ask for help}

While comprehensive student support systems are in place, it appears that Pasifika students may not see them as appropriate for their needs. All three participants identified difficulties with seeking help, demonstrated by the following:
It's not easy to ask for help, but that's just because we don't. We don't ask for help. We just kind of muddle on and do it. I know where to go if I need help. We've got the Student Success Team or whatever it is... (\#3)

\section{Determination to succeed}

The theme of determination to succeed was strongly seen in all three participants' comments. One student described the challenges of applying for the programme:
I think it put me off to start with, because I read it and read what I had to do, and I was like, "I can't do that." So I just didn't for a while and thought about it and then I was like, "Actually, I can do this." It's serious. They want good people and people that are going to succeed and if you can't do that then you can't do the programme. So I got it done. It was alright, it was just very full on. (\#3)

The notion of doing this to make the family proud and to be a role model for their children was important for all:
I have to have something to show for it at the end. So I have to keep pushing myself to succeed. It's going to be good for my son as well because he's going to see me succeeding. Whereas me and my brothers, we never really got that...

Another student contemplated withdrawing from the programme and identified the potential reaction of her children as a motivating factor: "It was either I was going to drop out or continue. Dropping out wasn't an option because then my kids would be thinking, 'Um, excuse me'..." (\#2).

This student described a desire to do further study, including wanting to work in midwifery education: "Now that I have a very definite goal, and goals beyond my degree goal, I'm very committed to my studies and how I succeed. So probably the determination that I've got through my studies as well has been huge" (\#3).

Another student describes what has motivated her to succeed:
Probably my age. I'm a bit old to be mucking around with study now. And I actually really want to do this. Before I was kind of... it was priority. I didn't prioritise study. Which was obviously related to not really wanting to achieve. But with this I have set goals and I want to achieve those goals. I'm excited for what a career in midwifery can lead to. (\#1)

\section{Desire to work with Pasifika women}

All three students wanted to work with Pasifika women, with one saying:
The more I've learnt this year about how indigenous people respond better healthwise to providers that are the same ethnicity as them, their health stats improve so much and I've seen it with Māori, and I thought, "Why do we not have this for Pacific Islanders as well, because would they not reap the same benefits if they had Pacific Island health providers?" (\#3)

\section{Student experience in the programme}

The next broad area that emerged was the student experience in the programme.

\section{The value of àkonga}

Students clearly identified that ākonga are valuable. One student said: I loved akonga group because that's where we built
relationships, connected with each other, and learnt about 
what was happening in their lives. And it wasn't all just talk about midwifery, it was talk about life; what's happening in our lives. It was a really important group I think for me. (\#2)

\section{The costs of the programme}

This student described the costs associated with the programme as:

\begin{abstract}
Massive. I don't actually know how I'm going to do third year, and I don't know how I'm going to juggle that with Mum either. Mum's the main carer for my child, when I have to go away to intensives and things, so third year is going to be a buge toll on the family...(\#3)
\end{abstract}

\section{Assignment writing}

There was plenty of feedback about assignment writing, with a student saying: "It's just that I don't like essay writing. I think why it's really annoyed me is that a majority of assessments we've done this year have been essays or writing in the form of an essay" (\#1).

She expanded: "I reflect a lot, I always reflect, but I don't like writing my reflections. It's almost like reflecting on your reflection and I struggle to put it into writing" (\#1).

Another student identified that she has struggled with the assignment questions, saying:

\begin{abstract}
For me personally, some of the wording of assignment questions are just quite bizarre to me and I really struggle to get my head around it. I don't know whether that's just a general thing across the board or whether that's specifically because of my Pacific Island background, I have no idea. (\#3)
\end{abstract}

\section{Preferring the face-to-face}

When discussing modes of learning in the blended programme one student stated that she found the online tutorials the least useful. She went on to say: "I suppose it's a part of distance learning that you can't really have the whole interaction that you would faceto-face" (\#1). When she was questioned further about whether she preferred classroom or this way of learning, she replied:

\section{Not classroom every day, definitely not. This blended learning works perfectly, because I still get to catch up with my äkonga every week. Then catch up with everyone else at intensives and stuff. There's still some face-to-face, but then I'm kind of left to do it myself, which kind of works in with the way that I like learning as well. (\#1)}

\section{Making connections}

A student articulated the importance of making a connection with the School early. She said: "I think having a connection with you straight off for those who identify as Pacific is really important" (\#2). This student also found it important to make connections with her fellow students:
It's really important that I'm doing it with someone else; that we're on the road together rather than individual. And doing work together I like to share; sit at a table and share stuff together with another person, which is what me and my mate did a lot. (\#2)

This student described the grief of losing one of her midwifery colleagues who withdrew from the programme:
I think my biggest issue in the beginning was making sure I'm taking someone with me; always doing it with someone, not being on my own. It's a very lonely programme. So if you don't make connections with the other students you're basically on your own. I think I struggled with that part the most, especially when my friend dropped out. I just thought,

"I don't want to do this now; I don't want to do this by myself". (\#2)

\section{Place to belong}

This student spoke about finding a place to belong. She had failed a course and then successfully completed the course the following year. She said:

It's also about becoming familiar with the space that you're in. I was more familiar now with the programme and how things start to get together and I was able to bring in my own life experiences that I didn't know how to bring in before. (\#2)

She expanded on the transition she made:

It was all new and I think even though I wanted to do it, I was still afraid. After that first year (which I think was the hardest in getting my head around everything as well as myself, getting over myself) it started to get better. (\#2)

\section{Collectivism}

When asked "What could the School do better to support you?" one student clearly outlined her collectivist outlook when she responded:
I don't know if there's anything. I'm sure there is. It's been such a long time. I just think having a better understanding of how we work. How Pacific work, function as a whole, is that everything is about us, our family, our community. It's not about individuals. It's not about me being me, sort of thing. It's about "us" always. So I'm down in Dunedin (at orientation), but I'm there with my whole family. When you're doing stuff, it's like there's a guy that spoke the other day and he said, "This is the problem with Pacific women: they come over here, they live in their homes as a family; as a unit. Everything is about the benefit of that family, it's not about the betterment of one individual. Then they go to school, and at school it's all about the individual". (\#2)

\section{DISCUSSION}

As we review the literature and compare this with our findings, the importance of finding a place to belong, the students' drive to succeed, the factors underpinning this drive and challenges faced, will be explored. The Spacifichology model will also be revisited for how it has contributed to an understanding of the students' experiences. Finally, a brief overview of how the School plans to address the findings will be provided.

\section{Fitting in and belonging as a Pasifika student}

Alkema (2014) highlighted the need for a "learning village", supporting students academically and pastorally in an environment where they felt comfortable. This aligns with the theme we uncovered of finding a place to belong.

The importance of belonging has been highlighted in other studies and has been shown as a way to build confidence and develop a positive identity (Furrer \& Skinner, 2003; Luafutu-Simpson et al., 2015; Mila-Schaaf \& Robinson, 2010; Osterman, 2000). Luafutu-Simpson and colleagues also stressed the importance of connections as the basis of relationships, and Tomoana (2012) recognised that relationships are of utmost importance as the foundation for learning.

A study exploring Pacific Island students' experiences at Massey University found that the students' social networks consisted primarily of other Pacific Islanders (Tofi, Flett, \& TimutimuThorpe, 1996) and Chu et al. (2013) found that Pasifika students had a preference for sticking together during the hard times. Likewise, the midwifery students in our study predominately formed alliances with other Pasifika and Māori students. 
The value of working together in educational institutions, where there was a privileging of Western cultural capital over other cultural world views, was recognised by the students in LuafutuSimpson et al.'s (2015) study. The students highlighted the value of working collectively, as opposed to the expectations of institutions that they become independent solitary learners (Luafutu-Simpson et al., 2015).

In the current study, the ākonga were identified as enabling students to work together. These groups provide a space for listening to students in a face-to-face environment, offering pastoral support as well as learning support. Further, they allow space for kaiako to get to know the students, and to create an environment where students feel they belong. These concepts have been acknowledged by Tomoana (2012) as helping students to succeed. Belonging to an ākonga also assists with creating a team environment so students feel comfortable to ask a class member or their kaiako for help. It also provides a place for students to give feedback, and for kaiako to check comprehension, and use a variety of formats to demonstrate practice skills. Tomoana (2012) acknowledges that making time in the teaching plan to listen to students creates gains in other areas and can be used as a strategy to build relationships and enhance learning.

Determination to succeed and the primacy of the family (us) $\mathrm{NZ}$ culture is often classified as individualist and its mode of education as dialogic with an emphasis on independent, self-directed and critical thinking (Ho, Holmes, \& Cooper, 2004). However, it is recognised that there is diversity in NZ's educational values and practices, some of which have been influenced by Māori and Pasifika communities, who have a more collectivist approach to learning (Ho, Holmes, \& Cooper, 2004). In collectivist cultures, people promote respect for authority and group consensus compared to individualist cultures, where selfexpression and individual thinking is emphasised (Ho, Holmes, \& Cooper, 2004). One of our students acknowledged her collectivist outlook when she stated "It's not about individuals...It's about 'us' always" (\#2).

Pasifika students have identified that their obligation to their family was seen as more important than study, which may negatively impact study or mean that the student would have to cease studying (Benseman, Coxon, Anderson, \& Anae, 2006). There were also expectations placed on them by their parents to attend church and family activities as well as study (Benseman et al., 2006; Future Workforce, 2009). Likewise, the learners in our study have discussed competing demands. Conversely, families that provide a meaningful level of support (such as through praise, giving students time to study, and encouraging higher education) assisted students to academic success (Chu et al., 2013).

Pasifika families often have few family members who have tertiary education experience, the consequence being there is less knowledge from which students can draw to help them build academic habits and receive guidance (Benseman et al., 2006).

Success was viewed by the students in Luafutu-Simpson et al.'s (2015) research as completion of a qualification, which was often followed by an explanation of how their achievement would positively impact family and the next generation. They were aware that being successful comes with great responsibility, including being good role models for younger siblings, their own children or future generations. They showed awareness of family sacrifice, and a reciprocal sense of service and responsibility that comes with success (Luafutu-Simpson et al., 2015). Similarly, the themes of role modelling and "giving back" were expressed by our learners.
However, the decision to commence tertiary education for Pasifika may be a mature decision after applicants realise the value of education following completion of secondary school (Benseman et al., 2006). The three participants in our study are all mature students with one stating "I've done life but I haven't done academic stuff to this extent” (\#2).

A challenge for some students, however, is knowing how to work the system and this mindset was identified as one of the major barriers to Pasifika students succeeding at tertiary level (Benseman et al., 2006). Students report that Pasifika students' cultural knowledge can be validated once the system is mastered (Benseman et al., 2006). This challenge resonates with a response from a student in our current study where she describes becoming familiar with the system:
It was all new and I think even though I wanted to do it, I was still afraid. After that first year (which I think was the hardest in getting my head around everything as well as myself, getting over myself) it started to get better. (\#2)

\section{Challenges in their programme and what could improve their experience}

Financial support has been recognised as a major issue for Pasifika students (Benseman et al., 2006; Chu et al., 2013; LuafutuSimpson et al., 2015). Students who had access to scholarships were less affected by monetary worries (Luafutu-Simpson, 2015) but limitations on student loans for older students may impact on the accessibility of education for Pasifika students. Placements are intensive and the associated costs are high for midwifery students, due to travel and accommodation requirements (Future Workforce, 2009). For midwifery students, the intensity and length of the programme affects students' ability to work during their study, potentially further compromising their ability to provide financially for themselves and their family. Further, there are low numbers of Pasifika academics to provide role modelling, mentorship and support (Benseman et al., 2006). This was recognised in our study, with one student suggesting that this gave her a goal to strive for (\#3).

\section{What the School is doing to improve their experience}

A common theme in supporting success for Pasifika students are programmes that demonstrate commitment to high achievement standards and the expectation that all students can achieve (Benseman et al., 2006). The expectation that all students can achieve is at the forefront of planning and in our relationships with students.

The School has made a commitment to more visibly include Pasifika culture and visual images in the programme material. We acknowledge that we do not have any Pasifika staff within our School and, therefore, it is of utmost importance to introduce the polytechnic's Student Advisor-Pasifika proactively and face-toface at the beginning of each year.

Tomoana (2012) suggests incorporating team building practices to encourage relationships amongst students. There is scope to increase cross-year shared time to enhance these relationships. Enhancement of the institutional interface with Pasifika students and Pasifika communities (Benseman et al., 2006) is an area for us to address as a School.

Students have identified that they struggle with the number of essays and reflections expected throughout the programme. In a recent redevelopment, the School has made significant reductions in the number of essays, with a focus on aligning practice courses with collaborative practical assessments. Our ongoing challenge is to ensure that essay questions, and expectations for what is required 
in reflections, are succinct, clear and explicit. Collaboration and group work are acknowledged as benefiting Pasifika learners (Luafutu-Simpson et al., 2015), and we continue to strategically incorporate these.

\section{STRENGTHS AND LIMITATIONS}

We acknowledge that this is a small study with just three participants. However, it did capture all the enrolled Pasifika students at the time. It is possible that a larger number of participants would have raised different issues and sentiments. However, many of the experiences resonate with those in other larger studies accessed in the discussion, such as the obligation to family and the desire to succeed. Further, it is possible that Pasifika students in other midwifery schools in NZ, or elsewhere, will recognise shared experiences in this study.

The Pasifika researcher brought value to the project and allowed the students to share candidly of their experiences. By using traditional communication strategies and acknowledging the cultural worth each student brought to the interview, the scene was set for exploring their views in an environment of trust.

The application of the Spacifichology model facilitated discussion of the unique aspects of each student's Pasifika connections with their families and their home nations, enabling them to share their individual connection to their cultural roots. While this model gave us a demographic profile of the students' cultural connection, the small number of participants did not allow deeper analysis of the student experience in relation to the categories in the Spacifichology model. In a larger study it would be expected that themes may emerge which pertain to the demographic categories in the Spacifichology model.

Importantly, the responses provide guidance for the School in the development of future curriculum and environmental design ideas that may resonate with other midwifery schools in relation to Pasifika students.

\section{CONCLUSION}

Pasifika students are challenged by competing demands from family and social responsibilities, financial issues and, for some, unfamiliarity with the tertiary education environment. Fostering a "learning village" will help students to feel that they fit in. The small ākonga groups in each satellite in the programme provide a place for the students to belong. As educators, we need to understand that it is always about "us" for Pasifika students; not about them as individuals. These findings provide insights for how midwifery programmes could be adapted to better support Pasifika learners.

Finally, these Pasifika students are determined to succeed, to represent their family, to be role models for younger Pasifika people, to benefit the Pasifika community and because they have a passion for midwifery.

\section{ACKNOWLEDGEMENTS AND CONFLICT OF INTEREST DISCLOSURE}

We would like to acknowledge Otago Polytechnic for funding our Pasifika researcher, Anna Seiuli, and to acknowledge Anna for her work with the students, the gift of the Spacifichology framework, and her collaboration with the research team which enabled the research team to facilitate the project. Thank you to Katie Baddock who transcribed the interviews for us. Our most special thanks to the students for the willing gift of their time and wisdom to the research project.

The authors declare that there are no conflicts of interest.

\section{REFERENCES}

Alkema, A. (2014). Success for Pasifika in tertiary education: Highlights from Ako Aotearoa-supported research (Report). Wellington, New Zealand: Healthrose Research Limited for Ako Aotearoa National Centre for Tertiary Teaching Excellence.

Benseman, J., Coxon, E., Anderson, H., \& Anae, M. (2006). Retaining non-traditional students: Lessons learnt from Pasifika students in New Zealand, Higher Education Research \& Development, 25(2), 147-162.

Chu, C., Samala Abella, I., \& Paurini, S. (2013). Educational practices that benefit Pacific learners in tertiary education (Summary Report). Wellington, New Zealand: Ako Aotearoa National Centre for Tertiary Teaching Excellence.

Cooperrider, D.L., \& Whitney, D. (2005). Appreciative inquiry: A positive revolution in change. San Francisco, United States of America: Berrett-Koehler Publishers.

External Pacific Advisory Committee. (2014). Otago Polytechnic Pasifika Strategic Framework 2015-2017. Dunedin, New Zealand: Otago Polytechnic. Retrieved from https://www.op.ac.nz/assets/Uploads/ Pasifika-Strategic-Framework-final.pdf.

Furrer, C., \& Skinner, E. (2003). Sense of relatedness as a factor in children's academic engagement and performance. Journal of Educational Psychology, 95(1), 148-162.

Future Workforce, District Health Boards New Zealand. (2009). Report on support for Māori and Pacific nursing and midwifery undergraduate students. Wellington, New Zealand: District Health Boards New Zealand. Ho, E., Holmes, P., \& Cooper, J. (2004, December). Review and evaluation of international literature on managing cultural diversity in the classroom (Report). Hamilton, New Zealand: University of Waikato, for Ministry of Education \& Education New Zealand.

Luafutu-Simpson, P., Moltchanova, E., O'Halloran, D., Petelo, L., Schischka, J., \& Uta'I, S. (2015). Change strategies to enhance Pasifika student success at Canterbury tertiary institutions. Wellington, New Zealand: Ako Aotearoa National Centre for Tertiary Teaching Excellence.

Midwifery Council of New Zealand. (2014). 2014 Midwifery Workforce Survey. Wellington, New Zealand: Author.

Midwifery Council of New Zealand. (2015). Standards for approval of pre-registration midwifery education programmes and accreditation of tertiary education organisation (2nd ed.). Wellington, New Zealand: Author.

Mila-Schaaf, K., \& Robinson, E. (2010). 'Polycultural' capital and educational achievement among NZ born Pacific Peoples. Mai Review, $1,1-18$.

Osterman, K.F. (2000). Students' need for belonging in the school community. Review of Educational Research, 70, 323-367.

Patterson, J., Newman, E., Kerkin, B., \& Wilson, K. (2013). What is the experience of Māori students in the blended Bachelor of Midwifery programme? (Report). Dunedin, New Zealand: Otago Polytechnic. Seiuli, A. (2013). Spacifichology. Paper presented at the Association of Pasifika Staff in Tertiary Education (APSTE) Conference, hosted by Massey University, Palmerston North, New Zealand.

Statistics New Zealand \& Ministry of Pacific Island Affairs (2010). Demographics of New Zealand's Pacific population. Wellington, New Zealand: Author.

Tofi, T., Flett, R., \& Timutimu-Thorpe, H. (1996). Problems faced by Pacific Island students at university in New Zealand: Some effects on academic performance and psychological wellbeing. New Zealand Journal of Educational Studies, 31(1), 51-59.

Tomoana, R. (2012). Sharing successful teaching and learning strategies for Māori, Pacific, and Youth learners: The Whitireia way 2012. Wellington, New Zealand: Ako Aotearoa National Centre for Tertiary Teaching Excellence.

Vaioleti, T. (2006). Talanoa research methodology: A developing position on Pacific research. Waikato Journal of Education, 12, 21-34.

\section{Accepted for Publication August 2018}

Beatson, D., Seiuli, A., Patterson, J., Griffiths C., \& Wilson, K. (2018). Pasifika student experience in a Bachelor of Midwifery programme. New Zealand College of Midwives Journal, 54, 44-50.

https://doi.org/10.12784/nzcomjnl54.2018.6.44-50 